\title{
Rapamycin-induced hyperglycemia is associated with exacerbated age-related osteoarthritis
}

\author{
Dennis M. Minton ${ }^{1,2}$, Christian J. Elliehausen ${ }^{1,2}$, Martin A. Javors ${ }^{3}$, Kelly S. Santangelo ${ }^{4}$ and \\ Adam R. Konopka ${ }^{1,2,5^{*}}$
}

\begin{abstract}
Background: The objective of this study was to determine if mechanistic target of rapamycin (mTOR) inhibition with or without AMP-activated protein kinase (AMPK) activation can protect against primary, age-related OA.

Design: Dunkin-Hartley guinea pigs develop mild primary OA pathology by 5 months of age that progresses to moderate OA by 8 months of age. At 5 months, guinea pigs served as young control $(n=3)$ or were fed either a control diet $(n=8)$, a diet enriched with the mTOR-inhibitor rapamycin (Rap, $14 \mathrm{ppm}, n=8)$, or Rap with the AMPKactivator metformin (Rap+Met, 1000 ppm, $n=8$ ) for 12 weeks. Knee joints were evaluated by OARSI scoring, microcomputed tomography, and immunohistochemistry. Glenohumeral articular cartilage was collected for western blotting.
\end{abstract}

Results: Rap- and Rap+Met-treated guinea pigs displayed lower body weight than control. Rap and Rap+Met inhibited articular cartilage mTORC1 but not mTORC2 signaling. Rap+Met, but not Rap alone, stimulated AMPK. Despite lower body weight and articular cartilage mTORC1 inhibition, Rap- and Rap+Met-treated guinea pigs had greater OA severity in the medial tibial plateau due to articular cartilage structural damage and/or proteoglycan loss. Rap and Rap+Met increased plasma glucose compared to control. Plasma glucose concentration was positively correlated with proteoglycan loss, suggesting hyperglycemic stress after Rap treatment was related to worsened OA.

Conclusions: This is the first study to show that Rap induced increase in plasma glucose was associated with greater OA severity. Further, articular cartilage mTORC1 inhibition and bodyweight reduction by dietary Rap and Rap+Met did not appear to protect against primary OA during the prevailing hyperglycemia.

Keywords: Aging, mTOR, AMPK, Dunkin Hartley guinea pig, Primary osteoarthritis

\section{Background}

Primary, age-related osteoarthritis (OA) is estimated to account for as many as $90 \%$ of all knee OA cases in humans [1]. However, preclinical research commonly relies on experimental models of secondary OA. Although primary and secondary $\mathrm{OA}$ share similar

\footnotetext{
*Correspondence: akonopka@medicine.wisc.edu

${ }^{5}$ Geriatric Research, Education, and Clinical Center, William S. Middleton

Memorial Veterans Hospital, Madison, Wisconsin, USA

Full list of author information is available at the end of the article
}

pathological outcomes, there is a growing body of evidence to suggest they are driven by distinct mechanisms. Retrospective analysis of differentially expressed genes from separate cohorts of primary and secondary OA patients relative to their healthy controls found that only $10 \%$ of differentially upregulated and $35 \%$ of differentially downregulated genes in $\mathrm{OA}$ vs non-OA samples are conserved between primary and secondary OA $[2,3]$. Therefore, $65-90 \%$ of differentially expressed genes may be unique to primary versus secondary OA. Additionally, otherwise in a credit line to the material. If material is not included in the article's Creative Commons licence and your intended use is not permitted by statutory regulation or exceeds the permitted use, you will need to obtain permission directly from the copyright holder. To view a copy of this licence, visit http://creativecommons.org/licenses/by/4.0/. The Creative Commons Public Domain Dedication waiver (http://creativecommons.org/publicdomain/zero/1.0/) applies to the data made available in this article, unless otherwise stated in a credit line to the data. 
transgenic animal models have revealed that several genes are differentially involved in the progression of primary and secondary OA [4-9]. For example, deletion of Panx3 protects against surgically induced OA yet dramatically worsens primary OA [4] and deletion of $J N K 1 / 2$ accelerates the development of primary OA while having no effect on surgically induced OA progression [9]. Together, these studies reinforce that unique mechanisms underpin these two forms of OA.

Age is one of the greatest risk factors for nearly every chronic disease, including primary OA. Two evolutionarily conserved kinases, mechanistic target of rapamycin (mTOR) and AMP-activated protein kinase (AMPK), are energy sensing pathways similarly dysregulated during aging and OA [10-13]. Providing the mTOR inhibitor rapamycin (Rap) in the diet can extend lifespan in mice and delay the onset of several age-related morbidities [12, 14]. However, despite slowing aging and delaying the onset of select age-related pathologies, Rap also has several notable side effects, including hyperglycemia, new onset diabetes, and dyslipidemia [15]. The antidiabetic drug metformin (Met) can activate AMPK and, when added to Rap, extends lifespan to a greater extent than historical cohorts of mice treated with Met or Rap alone and helps mitigate Rap-induced glucose intolerance $[16,17]$. While the prospect of lifespan extension is tantalizing, extending lifespan without delaying the onset or slowing the progression of the most debilitating age-associated conditions could be viewed as detrimental. Therefore, it is imperative to understand if purported lifespan-extending therapies that target the fundamental biology of aging are also capable of delaying the onset of chronic diseases, such as primary OA.

mTOR exists as complex I (mTORC1) and complex II (mTORC2). mTORC1 regulates cellular proliferation, protein synthesis, senescence, and survival while mTORC2 functions downstream of insulin signaling on substrates such as Akt [12]. In articular cartilage, mTORC1 activity increases with age and is sufficient to induce OA in young male mice [10]. In non-articular tissues, acute or intermittent Rap selectively inhibits mTORC1 while chronic Rap administration also inhibits mTORC2 activity [18]. Cartilage-specific deletion of the mTOR kinase and systemic or intra-articular injections of Rap and the mTORC1/2 inhibitor Torin 1 lower surgically induced $\mathrm{OA}$ in young-male mice and rabbits [19-22]. While these findings support mTOR-based therapeutics for OA, the completed studies were exclusively in injury-induced models of OA and have not been investigated in primary, age-related OA.

Recently, it has been proposed that the positive effects of mTOR inhibition on OA pathology may be diminished by feedback activation of PI3K and has raised questions about the need for a dual treatment strategy that inhibits both mTOR and upstream PI3K signaling [23, 24]. In addition to activating AMPK, Met has pleotropic effects including inhibition of PI3K signaling in rheumatoid arthritis fibroblast-like synoviocytes [25]. Moreover, Met and other AMPK-activators have chondroprotective effects against inflammatory-induced protease expression in vitro $[26,27]$ and protect against injury-induced OA in young male mice and rhesus monkeys [28]. Treatment with Met is also is associated with a lower rate of medial tibiofemoral cartilage volume loss and risk of total knee replacement in obese patients [29]. However, Met as an adjuvant therapy to Rap has not been investigated in primary OA.

The Dunkin-Hartley guinea pig is a well-characterized outbred model of primary OA. The progression of OA in guinea pigs is related to bodyweight [30] and shares a similar age-related and spatial progression to humans [31]. Additionally, changes in gene and protein expression in guinea pigs largely mimic those seen during OA progression in humans [32-37]. Mild OA pathology develops by 5 months in guinea pigs that progresses to moderate OA by $8-9$ months of age [31, 38, 39]. Therefore, at 5 months of age, we treated guinea pigs with lifespan-extending doses of dietary Rap (14 ppm) or a combination of dietary Rap+Met $(14+1000 \mathrm{ppm})$ for 12 weeks to slow the progression from mild to moderate $\mathrm{OA}$. This study is the first to evaluate if lifespan extending treatments can modify primary OA, the most prevalent form of OA observed in older adults.

\section{Methods}

\section{Animal use}

All tissues were collected at the University of Illinois Urbana-Champaign and approved by the Institutional Animal Care and Use Committee. Data collection and analysis were completed at University of WisconsinMadison and William S. Middleton Memorial Veterans Hospital. Because male Dunkin-Hartley guinea pigs develop more severe OA pathology than female [40], we used male animals to maximize the potential for the interventions to slow the progression of OA. Similar to previous work [41], male Dunkin-Hartley guinea pigs (Charles River) were singly housed in clear plastic, flat bottomed cages (Thoren, model \#6) with bedding. Guinea pigs were single housed to measure food consumption. Twelve-hour light/dark cycles were used beginning at 0600 . Guinea pigs acclimated for 2-3 weeks and were provided standard chow diet (Evigo 2040) fortified with vitamin C (1050 ppm) and vitamin D (1.5 IU/ $\mathrm{kg}$ ) and water ad libitum until 5 months of age. Guinea pigs were then euthanized to serve as young control $(n=$ 3) or randomized to continue the standard diet without 
eudagrit microcapsules $(n=8)$, or receive standard diets enriched with eudagrit encapsulated rapamycin (14 ppm, $n=8$ ) or the combination of encapsulated rapamycin plus metformin $(14+1000 \mathrm{ppm}, n=8)$ for 12 weeks. Guinea pigs were randomized to match bodyweight between groups prior to beginning treatment. Diets were enriched with microencapsulated rapamycin (Rapamycin holdings) and/or metformin (AK Scientific, I506) at concentrations previously shown to extend lifespan in mice $[14,16,42]$. Food consumption was recorded on Monday, Wednesday, and Friday between 8 and 9 AM, and body weight was recorded before feeding on Monday. Guinea pigs treated with Rap (14 ppm) or Rap+Met $(14+1000$ ppm) diet had ad libitum access to food. Dietary Rap (14 ppm) treatment has been shown to significantly reduce bodyweight in mice $[17,43]$. Therefore, we matched food consumption in the control group to the Rap diets to minimize the influence of food intake on dependent variables. One guinea pig in the Rap+Met group was euthanized early due to a wound on the gums which led to suppressed appetite and infection. Tissues from this animal were not collected for analysis. It could not be determined if this was due to a laceration or an oral ulcer, the latter of which is a known side effect of mTOR inhibitors [44].

\section{Tissue collection}

Two animals were sacrificed daily between 7 and $10 \mathrm{AM}$. Food and water were removed from the cages $2-4 \mathrm{~h}$ before euthanasia. Animals were anesthetized in a chamber containing $5 \%$ isoflurane gas in oxygen and maintained using a face mask with $1.5-3 \%$ isoflurane. Blood was collected by cardiac puncture followed by excision of the heart. The right hind limb was removed at the coxofemoral joint, fixed in $10 \%$ neutral buffered formalin (NBF) for $48 \mathrm{~h}$, and transferred to $70 \%$ ethanol until processed for histology. Glenohumeral cartilage was collected, snap frozen in liquid nitrogen, and stored at -80 ${ }^{\circ} \mathrm{C}$ for further analysis. Because testicular atrophy has been observed following Rap treatment [45], the left testicle was preserved in $10 \%$ NBF and weighed. Although tissues are commonly weighed before fixation, previous work demonstrates that fixation negligibly effects testicle weight in similarly sized animals [46].

\section{Analysis of experimental diets and blood}

Twenty-five-milligram samples of diets enriched with Rap (14 ppm) or the combination of Rap+Met $(14+$ $1000 \mathrm{ppm})$, and aliquots of whole blood $(n=4$ per group) were sent to the Bioanalytical Pharmacology Core at the San Antonio Nathan Shock Center to confirm drug concentrations in the diet and in circulation. Analysis was performed using tandem HPLC-MS as described previously [14, 47, 48]. Frozen aliquots of plasma were thawed to measure glucose and lactate concentrations using the YSI Biochemistry Analyzer (YSI 2900).

\section{Micro-computed tomography $(\mu \mathrm{CT})$}

Right hind limbs from half of each treatment group $(n=$ 4 per group) were scanned using a Rigaku CT Lab GX130 at $120 \mu \mathrm{A}$ and $110 \mathrm{kV}$ for $14 \mathrm{~min}$, achieving a pixel size of $49 \mu \mathrm{m}$. Scans were first processed in Amira 6.7 (ThermoFisher) where epicondylar width was measured and a series of dilation, erosion, filling, and image subtraction functions were used to isolate trabecular and cortical bone as described previously [49]. Scans were then resliced 4 times along axes perpendicular to medial and lateral tibial and femoral articular surfaces and binarized using identical thresholds. NIH ImageJ software and BoneJ plugin were used to quantify thickness, spacing, and volume fraction measurements. Cortical thickness was measured by placing polygonal regions of interest (ROI) in resliced scans to encompass the articular surfaces in each joint compartment. Trabecular thickness, spacing, and bone volume fraction were measured by placing transverse ROIs $(2.4 \times 2.4 \times 1 \mathrm{~mm})$ in the trabecular bone of each joint compartment.

\section{Histology}

Knee joints were decalcified in a $5 \%$ ethylenediaminetetraacetic acid, changed every 2-3 days for 6 weeks. Joints were then cut in a coronal plane along the medial collateral ligament, paraffin embedded, and sectioned at $5 \mu \mathrm{m}$ increments for Toluidine Blue staining and immunohistochemistry (IHC). Slides were scanned using the Hamamatsu NanoZoomer Digital Pathology System, providing $460 \mathrm{~nm}$ resolution. Scan focus points were set manually along the articular cartilage. Imaged slides were then scored by two blinded reviewers for OA severity following OARSI modified Mankin guidelines as described [39]. Briefly, toluidine blue stained histology slides were assigned scores for severity of articular cartilage structural damage (0-8), proteoglycan content loss as assessed by absence of toluidine blue staining (0-6), disruption of chondrocyte cellularity (0-3), and tidemark integrity $(0-1)$, with a total possible score of 18 per joint compartment (Total OARSI Score). One guinea pig each from the Rap and Rap+Met groups was unable to be analyzed due to off-axis transection before embedding. One control animal was a statistical outlier as detected by Grubb's test and was excluded from the study. Therefore, $n=7$ per group were used for histopathological analysis.

\section{Immunohistochemistry}

Antigen retrieval was performed in $10 \mathrm{mM}$ sodium citrate for $7 \mathrm{~h}$ at $60{ }^{\circ} \mathrm{C}$. Endogenous peroxidase activity 
was quenched using $3 \% \mathrm{H}_{2} \mathrm{O}_{2}$ for 15 min before blocking in 5\% normal goat serum diluted in TBST for $1 \mathrm{~h}$ at RT. Slides were incubated overnight in $200-300 \mu \mathrm{L}$ of either p-RPS6 (1:200 dilution; Cell Signaling, 4858) or a rabbit IgG isotype control (Cell Signaling, 3900) diluted to match primary antibody concentration. Primary antibodies against p-Akt Ser473 (1:100 dilution; 4060) and p-AMPK Thr172 (1:200 dilution; 50081) from Cell Signaling were attempted, but reactivity was not seen in guinea pig articular cartilage. One hundred and fifty to $200 \mu \mathrm{L}$ of goat anti-rabbit secondary antibody (Cell Signaling, 8114) was added for $1 \mathrm{~h}$ at room temperature followed by exposure in 3,3'-diaminobenzadine (DAB; Cell Signaling, 8059) for $10 \mathrm{~min}$. Slides were then counterstained using hematoxylin, dehydrated, and cleared through graded ethanol and xylene, coverslipped using Permount (Electron Microscopy Sciences), and viewed and imaged under a brightfield microscope. No DAB staining was seen following incubation with the IgG control or secondary antibody alone, confirming specificity of the primary antibody. For quantification, ROIs were placed to encompass areas of staining in the medial tibial articular cartilage, and cells were counted to determine the percent-positive cells. For intensity-based quantification, a color deconvolution for DAB staining was applied in ImageJ, and mean integrated intensity was quantified by averaging two p-RPS6 replicates and subtracting background staining of IgG controls.

\section{Western blot}

Cartilage was removed from the glenohumeral joint using a scalpel and placed in reinforced Eppendorf tubes containing $500 \mathrm{mg}$ of ceramic beads (Fisher, 15-340-160) and $200 \mu \mathrm{L}$ of RIPA buffer with protease and phosphatase inhibitors (Sigma, 5892970001), and homogenized by 2, 30 -s cycles at $6 \mathrm{~m} / \mathrm{s}$ in the Omni BeadRuptor. Homogenate was transferred to microcentrifuge tubes and spun at $10,000 \times g$ for $10 \mathrm{~min}$ at $4{ }^{\circ} \mathrm{C}$. Supernatants were diluted to equal concentration following a BCA assay. Samples were prepared in reducing conditions with $\beta$-mercaptoethanol in 4x Laemmli Sample Buffer (BioRad, 1610747) and heated at $95^{\circ} \mathrm{C}$ for $5 \mathrm{~min}$. Ten micrograms of protein was separated on 4-15\% TGX precast gels (BioRad, 4561083) and transferred to PVDF membranes (BioRad, 1620177). Membranes were blocked in TBST with 5\% bovine serum albumin (Sigma, A9647) for $1 \mathrm{~h}$ at RT and incubated overnight at $4{ }^{\circ} \mathrm{C}$ in primary antibodies against p-RPS6 Ser235/236 (4858), RPS6 (2217) p-Akt Ser473 (4060), Akt (4685), P-AMPK Thr172 (50081), AMPK (2532), and LC3B (3868) from Cell Signaling and ADAMTS5 (ab41037), MMP13 (ab39012), and b-Actin (ab8226) from Abcam. HRP-conjugated anti-Rabbit (Cell Signaling) or anti-Mouse (Abcam) secondary antibodies were diluted 1:5000 for all proteins except b-Actin (1:10,000 dilution). All membranes were imaged using a UVP BioSpectrum 500 (UVP) following 5-min incubation in a 2:1 combination of SuperSignal Pico (Fisher, 34577) and Femto (Fisher, PI34095) chemiluminescent substrates except b-Actin which received Pico alone. Densitometric analysis was performed using VisionWorks (Analytikjena). Phosphorylated proteins are expressed relative to their total protein and other targets are expressed relative to b-Actin.

\section{Statistical analysis}

Previous work demonstrated that a sample size of $n=6$ is adequately powered to detect changes between groups in guinea pigs [41]. Therefore, we a priori determined our sample size ( $n=7-8$ per group) to be appropriate to detect differences between treatment groups. All data were subjected to normality testing via the Shapiro-Wilk test. A two-way repeated measures ANOVA (time $\times$ treatment) was performed to determine differences in food consumption and body weight. For all other variables, a one-way ANOVA comparing the difference between each treatment and 8-month controls was performed. Upon a significant interaction, HolmSidak's multiple comparisons test was used. Data with non-Gaussian distribution were compared using nonparametric Mann-Whitney tests or the Kruskal-Wallis test followed by Dunn's multiple comparisons test and noted in the figure legend. Pearson's $\mathrm{R}$ was used to determine correlation between variables. $P$-values $<0.05$ were considered statistically significant. Data are presented as scatter plots with mean or mean \pm standard deviation (SD).

\section{Results \\ Influence of rapamycin and rapamycin+metformin on guinea pig physical and metabolic characteristics}

Figure 1A shows the average daily food consumption per week of standard diet or standard diet enriched with Rap $(14 \mathrm{ppm})$ or Rap+Met $(14+1000 \mathrm{ppm})$. The average daily intakes of Rap and Met based on food consumption and dietary concentration are reported in Table 1. Compared to control, there was decreased food consumption in guinea pigs receiving Rap+Met $(14+1000 \mathrm{ppm})$ during week $2(P=0.04)$. There were no significant differences between treatments. Despite largely matching food intake, there was a significant effect for treatment $(P=$ $0.004)$ and an interaction between time and treatment $(P$ $<0.0001)$ on bodyweight. Dietary Rap + Met $(P=0.01)$ and Rap-treated guinea pigs $(P=0.02)$ weighed less than control starting at week 3 and week 4 , respectively, until the end of the study (Fig. 1B). At time of death, dietary 


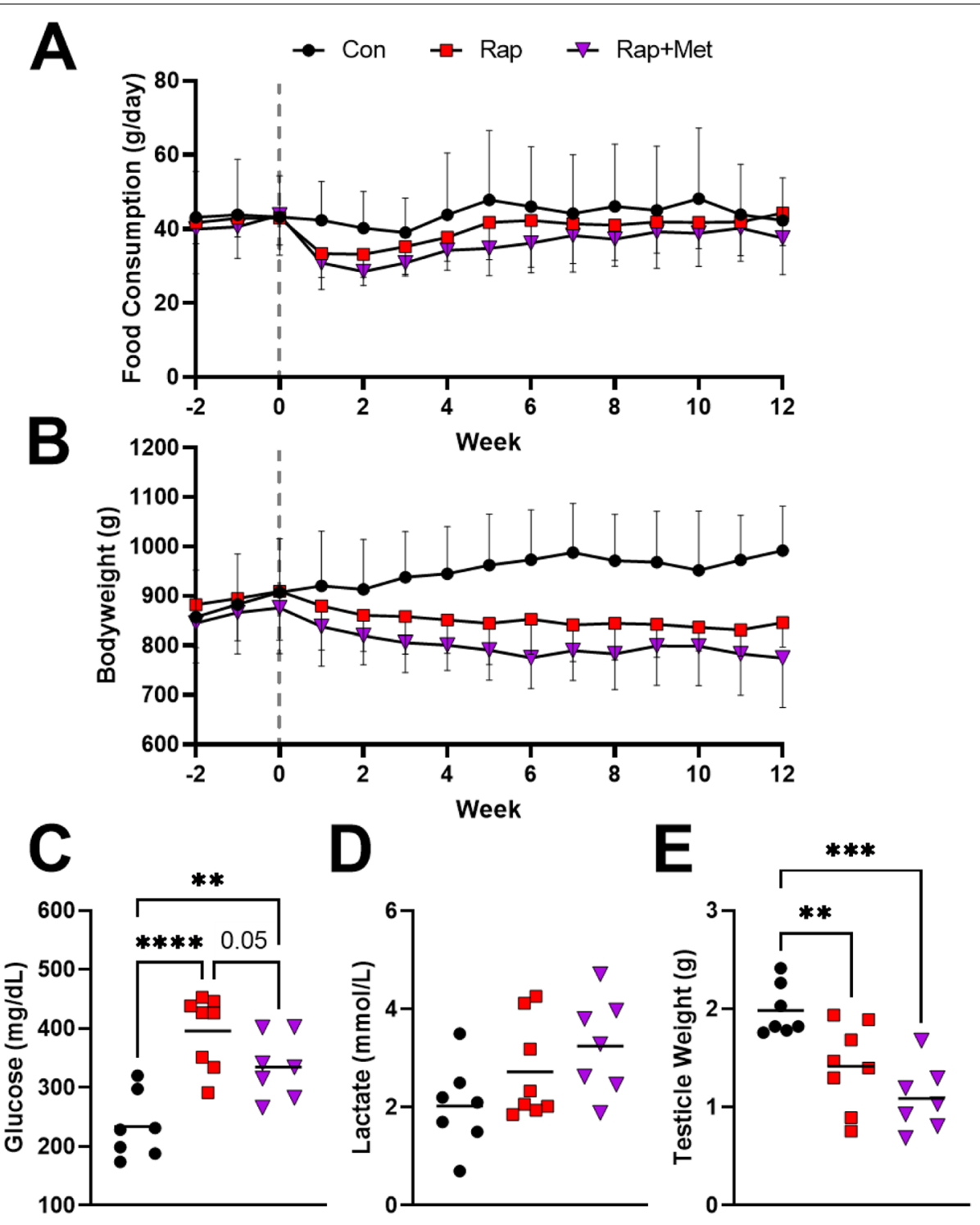

Fig. 1 Characterization of animals on experimental diets. Food consumption $(\mathbf{A})$ and bodyweight $(\mathbf{B})$ of guinea pigs were recorded for the duration of the study (data presented as mean \pm SD). Data analyzed using a two-way ANOVA to detect treatment by time interaction. Plasma glucose (C), lactate (D), and testicle weight (E) are shown. Data were analyzed using a one-way ANOVA to detect differences between groups for all variables besides lactate, for which differences were determined using the non-parametric Kruskal-Wallis test with Dunn's multiple comparison test. ${ }^{* *} P<$ 0.01 vs Con, ${ }^{* * *} P<0.001$ vs Con, ${ }^{* * *} P<0.0001$ vs Con

Rap $(P=0.002)$ and Rap + Met-treated guinea pigs $(P=$ 0.001 ) weighed $15 \%$ and $22 \%$ less than control.

Compared to control, treatment with dietary Rap (14 ppm) and Rap+Met $(14+1000 \mathrm{ppm})$ increased $(P<$ 0.01) plasma glucose (Control, $234 \pm 55 \mathrm{mg} / \mathrm{dL}$, vs Rap, $396 \pm 61 \mathrm{mg} / \mathrm{dL}$, vs Rap+Met, $334 \pm 53 \mathrm{mg} / \mathrm{dL}$ ) while the addition of Met to Rap lowered plasma glucose compared to Rap alone $(P=0.05$; Fig. $1 C)$. Lactate concentration trended to be elevated by $66 \%$ in Rap+Met-treated guinea pigs, only ( $P=0.1$; Fig. $1 \mathrm{D})$. Testicle weight in guinea pigs receiving $\operatorname{Rap}(P=0.01)$ and $\operatorname{Rap}+\operatorname{Met}(P=$ 0.0004 ) were $27 \%$ and $44 \%$ lower than control, respectively, suggesting gonadal atrophy (Fig. 1E). We analyzed blood for the circulating Rap and Met concentrations $3 \mathrm{~h}$ after food had been removed from the cage (Table 2). This timing aligns with a measurement of peak circulating Rap and Met. We show that experimental diets were sufficient to increase Rap and Met concentrations in the blood, and that Rap values were not different when providing diets individually or in combination. In control 
Table 1 Average consumption of rapamycin and metformin. Using the concentration of rapamycin and metformin from the diet analysis, the average doses were calculated for each group in $\mathrm{mg}$ of drug per $\mathrm{kg}$ body weight per day ( $\mathrm{mg} / \mathrm{kg} /$ day). $N=7-8$ per group. Data are presented as mean \pm SD

\begin{tabular}{lll}
\hline & Experimental Diet & \\
\cline { 2 - 3 } & Rapamycin & Rapamycin+Metformin \\
\hline $\begin{array}{l}\text { Rapamycin con- } \\
\text { sumed (mg/kg/day) }\end{array}$ & $0.72 \pm 0.09$ & $0.68 \pm 0.08$ \\
$\begin{array}{l}\text { Metformin consumed } \\
\text { (mg/kg/day) }\end{array}$ & - & $45 \pm 5.6$ \\
\hline
\end{tabular}

Table 2 Concentrations of rapamycin and metformin in circulation. Whole blood was collected $\sim 3 \mathrm{~h}$ after food had been removed from the cages of guinea pigs and was analyzed for rapamycin and metformin concentration by tandem HPLC/ MS. $N=4$ per group. The blood concentration of rapamycin and metformin in the control group were below the detectable limits of the HPLC/MS/MS. Data are presented as mean \pm SD

\begin{tabular}{llll}
\hline & \multicolumn{2}{l}{ Experimental Diet } \\
\cline { 2 - 4 } & Control & Rapamycin & Rapamycin+Metformin \\
\hline $\begin{array}{l}\text { Circulating } \\
\text { rapamycin } \\
\begin{array}{l}\text { (ng/mL) } \\
\text { Circulating }\end{array}\end{array}$ & $<0.5 \pm 0$ & $72 \pm 8$ & $78 \pm 10$ \\
$\begin{array}{l}\text { metformin } \\
(\mathrm{ng} / \mathrm{mL})\end{array}$ & & & \\
\hline
\end{tabular}

animals, circulating levels of Rap or Met were below detectable limits.

\section{Dietary rapamycin (14 ppm) and rapamycin+metformin $(14+1000 \mathrm{ppm})$ treatment exacerbated the age-related progression of $O A$}

Consistent with the age-related progression of mild to moderate $\mathrm{OA}$ in guinea pigs, we observed an increase in medial tibial total OARSI score from 5 to 8 months $(P=0.03$; Figure S1A-B). Surprisingly, dietary Rap and Rap+Met treatment resulted in a $\sim 2$-fold increase in total OARSI score in the medial tibial plateau compared to 8 month old, age-matched control $(P=0.02$ for both Rap and Rap+Met; Fig. 2B). This was driven by increased scores for articular cartilage structure $(P=0.03$ for Rap, $P=0.1$ for Rap + Met; Fig. $2 \mathrm{C})$ and proteoglycan loss $(P$ $=0.02$ for Rap and Rap+Met; Fig. 2D), while there was no differences between groups for cellularity (Fig. 2E). We observed minimal tidemark duplication and no osteophyte formation across groups. OA scores in lateral tibia or medial or lateral femur were lower than the medial tibial plateau and there was no significant effect of Rap or Rap+Met on the OARSI score for these joint compartments (Figure S1C).

\section{OA pathology was correlated to plasma glucose, bodyweight, and testicle weight}

Because dietary Rap- (14 ppm) and Rap+Met- $(14+$ $1000 \mathrm{ppm}$ ) treated guinea pigs displayed several common side effects of Rap, including increased plasma glucose, testicular atrophy, and decreased bodyweight, we evaluated the relationship between these variables and measures of OA severity across all guinea pigs. Plasma glucose was positively correlated to proteoglycan loss $\left(R^{2}=0.19 ; P=0.04\right.$; Fig. $\left.3 \mathrm{~A}\right)$, and total OARSI score was negatively correlated with both bodyweight $\left(R^{2}=0.19 ; P=0.04\right.$; Fig. $\left.3 \mathrm{~B}\right)$ and testicle weight $\left(R^{2}\right.$ $=0.20 ; P=0.04 ;$ Fig. $3 C)$. However, because testicle weight and bodyweight were also related (data not shown), the individual contribution of these variables cannot be distinguished.

\section{Effects of dietary rapamycin (14 ppm) and rapamycin+metformin $(14+1000$ ppm) on mTOR, AMPK, and protease expression}

To evaluate mTORC1 signaling in articular cartilage, we measured the phosphorylation of ribosomal protein S6 (P-RPS6) at Ser235/236 using IHC and western blotting. Representative images of P-RPS6 IHC are shown in Fig. 4A. P-RPS6 was decreased by $90-95 \%$ in the medial tibial articular cartilage of Rap- and Rap+Met-treated guinea pigs as assessed by percentage of P-RPS6-positive cells $(P=0.001$ for Rap, $P=0.01$ for Rap+Met; Fig. 4B), and by staining intensity $(P=$ 0.03 for both; Fig. 4C). mTORC1 inhibition was further supported by an $81 \%$ lower ratio of phosphorylated to total RPS6 in glenohumeral cartilage from Rap $(P$ $=0.007$; Fig. 4E) while Rap+Met trended to decrease RPS6 phosphorylation by $48 \%(P=0.1)$. There was a non-signficant increase in the phosphorylation of the mTORC2 substrate Akt at Ser473 in Rap or Rap+Met compared to control (Fig. 4F; $P=0.1$ ). AMPK activation was measured using western blot to assess phosphorylation of AMPK at Thr172 (P-AMPK). P-AMPK was not changed by Rap alone $(P=0.9$; Fig. $4 \mathrm{G})$ but tended to be elevated by $77 \%$ by Rap+Met $(P=0.07)$. Notably, AMPK phosphorylation was elevated in Rap+Met compared to Rap alone $(P=0.009)$. Rap or Rap + Met did not significantly change the conversion of LC3B I to II ( $P>0.99$ for both; Fig. $4 \mathrm{H})$. A disintegrin and metalloproteinase with thrombospondin motifs 5 (ADAMTS5; Fig. 4I: $P=0.99$ for Rap, $P=0.05$ for Rap+Met) and matrix metalloproteinase 13 (MMP13; Fig. 4J: $P=0.99$ for Rap, $P=0.1$ for Rap + Met) was 


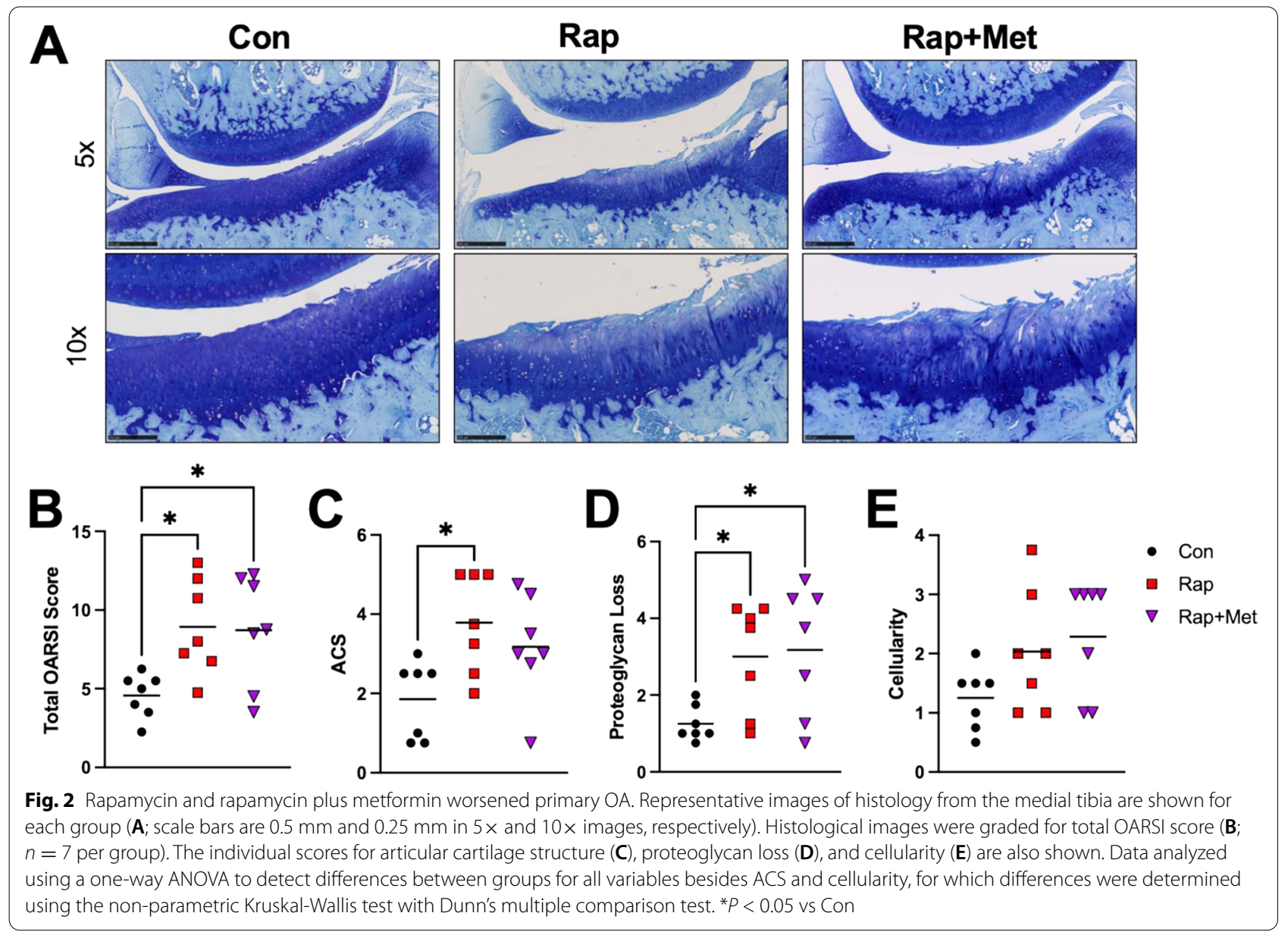

unchanged by Rap but trended higher in Rap+Met. Unless otherwise noted, there were no significant differences between Rap and Rap+Met.

\section{Dietary rapamycin (14 ppm) and rapamycin+metformin $(14+1000$ ppm) decreased subchondral and diaphyseal bone thickness}

Representative microCT images shown in Fig. 5A were used to quantify the effect of experimental diets on subchondral bone parameters. Mean subchondral cortical thickness was decreased by dietary Rap and Rap+Met in the medial (29\%, $P=0.005$ for Rap; $23 \%, P=0.01$ for Rap+Met) and lateral (21\% for Rap; $20 \%$ for Rap+Met; $P=0.02$ for both) tibia (Fig. 5B). Rap decreased cortical thickness in the medial femur $(18 \%, P=0.04)$. Rap and Rap + Met decreased trabecular spacing by $15 \%$ and $16 \%$, respectively, in the lateral tibia only $(P=0.006$ for both; Figure S2B). Trabecular thickness, trabecular spacing in other compartments, and bone volume fraction were not affected by any experimental diets (Figures S2A-C). Further investigation revealed that cortical thickness at the femoral diaphysis was also decreased by $\operatorname{Rap}(P=0.001)$ and Rap+Met $(P=0.02$; Fig. $5 C)$, and this change was proportionate to the decrease observed in the medial tibial subchondral bone (Fig. 5D). Further, medial tibial cortical thickness was correlated to bodyweight $\left(R^{2}=0.47, P\right.$ $=0.01$; Fig. $5 \mathrm{E}$ ), suggesting the smaller body mass of Rapand Rap+Met-treated guinea pigs may have contributed to decreased cortical thickness. Femoral epicondylar width (Fig. 5F) was not statistically different between groups (Rap, $P=0.42$; Rap+Met, $P=0.45$ ), suggesting our treatments did not affect skeletal development.

\section{Discussion}

The purpose of this study was to test if dietary Rap (14 $\mathrm{ppm})$ or Rap+Met $(14+1000 \mathrm{ppm})$ could delay the onset of age-related OA in the outbred Dunkin-Hartley guinea pig. We found that at concentrations shown to extend lifespan, dietary Rap (14 ppm) and Rap+Met $(14+1000 \mathrm{ppm})$ inhibited mTORC1 but not mTORC2 signaling in articular cartilage, and Rap+Met increased AMPK phosphorylation. Surprisingly, guinea pigs treated with dietary Rap (14 ppm), with or without Met $( \pm 1000$ $\mathrm{ppm}$ ), developed greater age-related OA compared to 


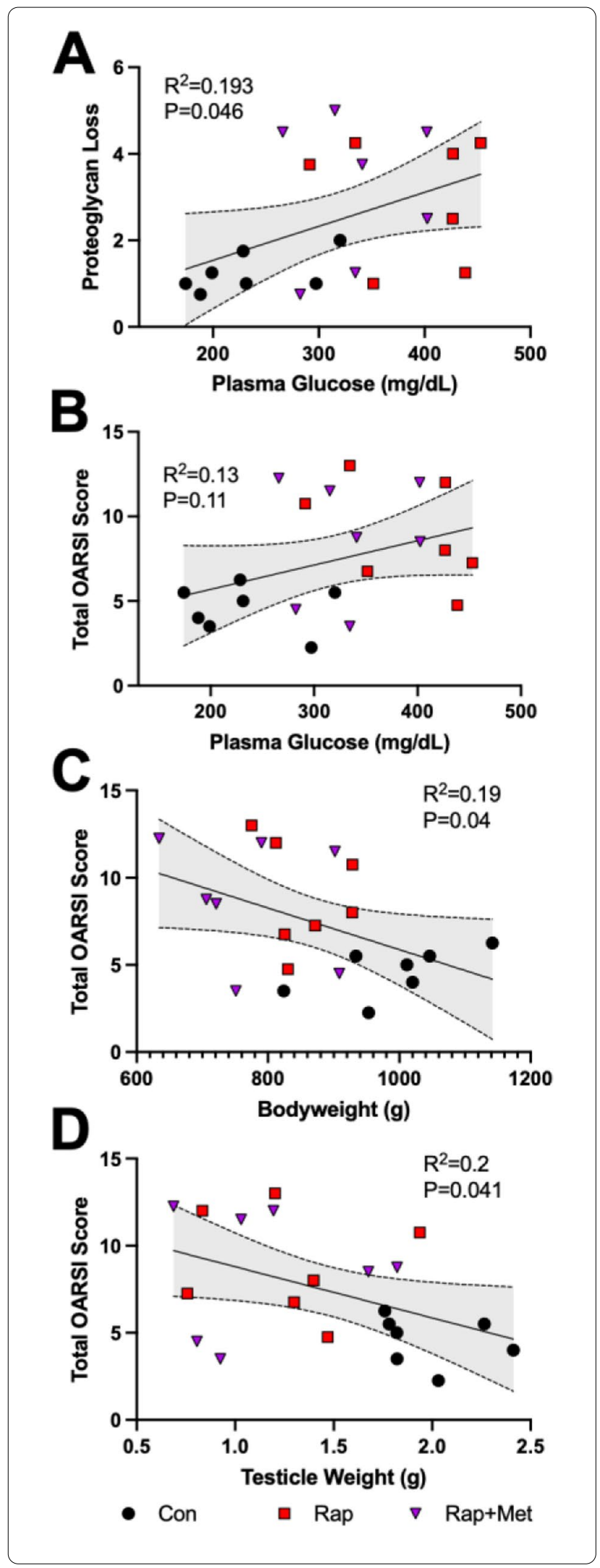

Fig. 3 Proteoglycan loss correlated with hyperglycemia. Correlations between proteoglycan loss and plasma glucose (A), bodyweight and total OARSI score $(\mathbf{B})$, and testicle weight and total OARSI score $(\mathbf{C})$ are shown. Data analyzed using the Pearson correlation. Shaded bands represent $95 \% \mathrm{Cl}$

control. Guinea pigs receiving dietary Rap (14 ppm) and Rap+Met $(14+1000 \mathrm{ppm})$ also displayed increased plasma glucose, which correlated with proteoglycan loss. These findings indicate that off-target hyperglycemic side effects of dietary Rap (14 ppm) are associated with greater hallmarks of OA pathology. Further, in the face of these Rap-induced side effects, mTORC1 inhibition may not slow the progression of age-related OA in Dunkin Hartley guinea pigs.

Despite inhibiting mTORC1 in articular cartilage, our findings indicate that guinea pigs treated with dietary Rap, with or without Met, had exacerbated age-related $\mathrm{OA}$ in the medial tibial plateau. Further, dietary Rap- (14 $\mathrm{ppm})$ and Rap+Met- $(14+1000 \mathrm{ppm})$ treated guinea pigs had greater total OARSI scores than age-matched control animals even though they weighed less, which is contrary to previous work where lower body weight was accompanied by lower OA scores in guinea pigs [30]. Although there is precedent that mTORC1 inhibition by intra-articular injection of Rap is associated with exacerbated temporomandibular joint (TMJ) OA [50], our findings were opposite of our original hypothesis and previous results using Rap in injury-induced models of knee OA $[19,20]$. In our study, Rap and Rap+Met treatment inhibited mTORC1 but not mTORC2 in articular cartilage. Previous work has shown that deleting articular cartilage mTOR [22] or treating with Rap $[19,20]$ or Torin-1 [21] can attenuate injury or chemical-induced $\mathrm{OA}$ in mice and rabbits. These non-selective genetic and pharmacological methods likely disrupt the entire mTOR kinase and therefore could inhibit both mTORC1 and mTORC2 signaling. However, this remains speculative as mTORC2 signaling was not evaluated in these previous studies, and it continues to be unknown if mTORC2 inhibition is necessary for protection against either primary or secondary OA. Further investigation is needed to resolve the role of each mTOR complex in the initiation, progression, and treatment of both primary and secondary OA.

While the dose of Rap in guinea pigs was similar to the dose shown to protect against injury-induced OA in mice ( $0.7 \mathrm{vs} 1 \mathrm{mg}$ of rapamycin per $\mathrm{kg}$ body weight per day in guinea pigs vs. mice) [19], after correcting for differences in pharmacokinetics between animals with vastly different body weight, allometric scaling [51] suggests the guinea pig equivalent dose was double that of mice. 


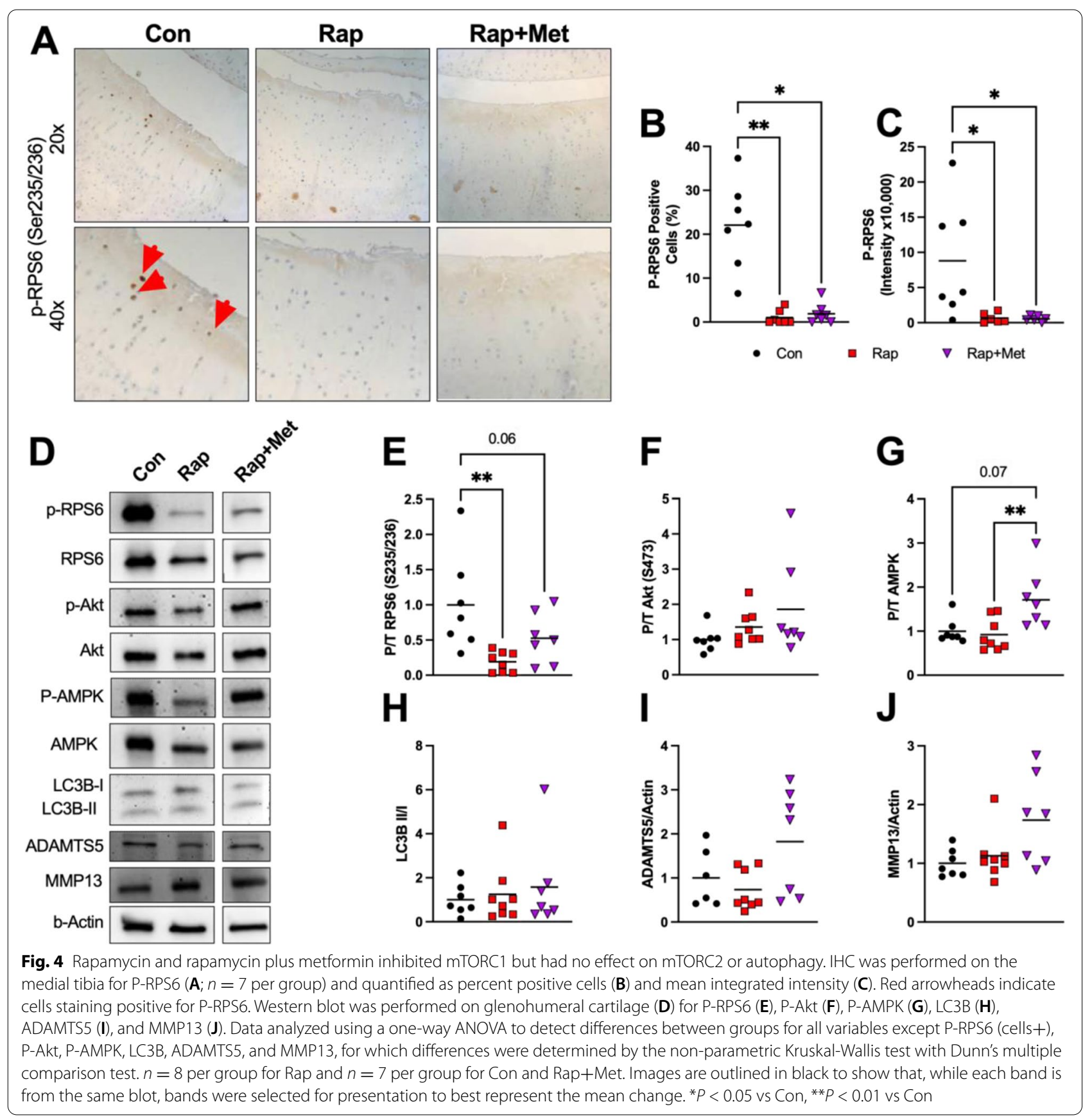

However, the guinea pigs in the current study received the same dietary concentration (14 ppm) and achieved similar circulating Rap concentrations shown to extend lifespan and decrease select age-related pathologies in mice involved in the NIA Interventions Testing Program [14]. Further, allometric scaling indicates that dietary Rap (14 ppm) elicited similar doses of rapamycin between guinea pigs in the current study and long-lived mice in the ITP.
Despite its lifespan and potential healthspan-extending effects, chronic Rap treatment is commonly associated with several metabolic and immunological side effects across diverse species including glucose intolerance, new onset diabetes, hypertriglyceridemia, immunosuppression, testicular atrophy, lower body weight, and cataracts $[18,45,52]$. Consistent with this, we showed that 12 weeks of dietary Rap (14 ppm) and Rap+Met $(14+1000$ ppm) was accompanied by increased plasma glucose, 


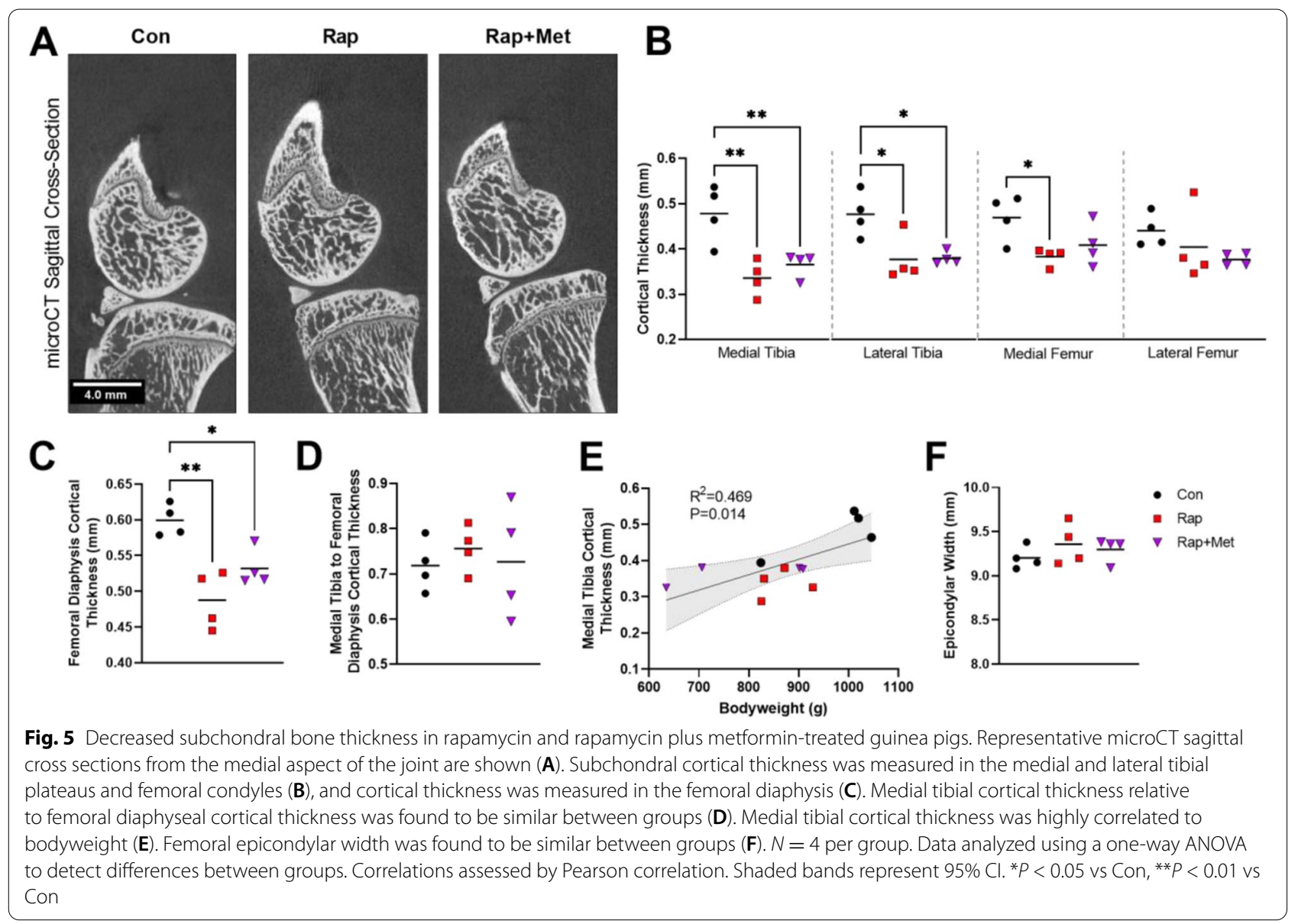

testicular atrophy, and lower body weight compared to controls. The glucose values induced by dietary Rap (14 ppm) and Rap+Met $(14+1000$ ppm) are comparable to previous studies that have induced diabetes in guinea pigs $[53,54]$. While there are no criteria to confirm a diabetes diagnosis in guinea pigs and we cannot directly compare between different studies, these findings are in line with rapamycin promoting new onset diabetes.

Despite increasing AMPK activity in articular cartilage and partially restoring glucose levels compared to Rap alone, the addition of the antihyperglycemic drug Met to Rap did not offer significant protection against the detrimental effects of dietary Rap on OA pathology. In our study, medial tibial proteoglycan loss was correlated with plasma glucose, and we propose that Rap-induced hyperglycemia may have contributed to worsened OA following dietary Rap. In support of this hypothesis, diabetic mice show more severe OA after injury and high glucose suppresses autophagy activation and can increase MMP13, IL-6, and NFkB in chondrocytes [55-61]. Rap has been implicated in attenuating secondary OA by increasing autophagy and decreasing protease expression
$[19,20]$. In our study, we observed no effect by any treatment on the lipidation of the autophagy marker LC3B while Rap+Met trended to increase ADAMTS5 and MMP13 in glenohumeral cartilage. Therefore, the inability to increase markers of autophagy and decrease proteases may be contributing factors to why our treatments did not protect and even worsened OA during aging and hyperglycemia.

Intermittent intraperitoneal injections of Rap lowered glucose and injury induced OA severity in diabetic mice [62]. It is possible in the current study that Rap did offer partial protection against hyperglycemic stress but still resulted in greater OA pathology than control. However, this remains speculative as we did not have a group exposed to hyperglycemic stress alone. Previous work suggests Rap can have divergent effects where it is beneficial in some diabetic models but causes adverse side effects in metabolically healthy models $[18,63]$. Collectively, these data suggest that the adverse metabolic side-effects of dietary Rap treatment are associated with a deleterious impact on primary OA pathology and could 
limit the utility of chronic Rap as a healthspan extending treatment.

Treatment with dietary Rap and Rap+Met also decreased subchondral cortical bone thickness in the medial and lateral tibia and the femoral diaphysis. As bone growth in guinea pigs ceases by 4 months [64], and epicondylar width was not different between groups, the differences in bone thickness were likely not the result of disrupted development. Decreased subchondral thickness was only observed in the tibia. Intra-articular injection of Rap into the TMJ caused subchondral bone loss by inhibiting pre-osteoblast proliferation [50], and Rap treatment also decreased osteoblast differentiation and bone matrix synthesis [65], which supports the idea that Rap can act directly on the bone to decrease thickness. However, we also found that subchondral thickness was highly correlated to bodyweight. This is in line with Wolff's law and agrees with previous findings where bodyweight restriction decreased cortical bone thickness in the femoral diaphysis [66]. Therefore, both local and systemic effects of Rap likely contributed to reduced cortical bone thickness.

Although we provide new insight into the role of mTOR during primary OA progression, we recognize some study limitations. While the guinea pig is an excellent model of primary OA, molecular probes are seldom designed for reactivity with guinea pigs. Due to reactivity issues with IHC in guinea pig cartilage (Figure S3), some of our analyses relied on western blot from glenohumeral cartilage. Although guinea pigs also develop mild glenohumeral OA [31], this is not the site at which we measured OA pathology. Our study could not conclusively determine if the deleterious effects of dietary Rap (14 ppm) stemmed from its direct effects on the joint or offtarget effects on other tissues. However, our data suggest hyperglycemia induced by off-target actions of Rap was associated with greater proteoglycan loss. This relationship could have been further strengthened by the addition of a group of guinea pigs exposed to hyperglycemic stress without Rap. The Dunkin Hartley guinea pig is an outbred model of primary OA which leads to inherent variability. While this could be perceived as a limitation, we contend that the variability and the choice of animal model adds translational value since this more closely recapitulates the genetic diversity and OA heterogeneity in humans. Despite these limitations, this does not detract from the findings that guinea pigs treated with dietary Rap (14 ppm) and Rap+Met $(14+1000$ ppm) had worse OA. Further, the presence of largely overlapping and consistent deleterious outcomes in both groups receiving dietary Rap increases our confidence that the side effects accompanying Rap contribute to worsened primary OA.

\section{Conclusion}

In summary, we have shown that at doses previously shown to extend lifespan, dietary Rap (14 ppm) and Rap+Met $(14+1000 \mathrm{ppm})$ caused hyperglycemia and was associated with aggravated OA in Dunkin Hartley guinea pigs despite inhibiting mTORC1 in articular cartilage. Treatments that extend lifespan without a proportionate delay in age-related chronic diseases and disabilities are counter to the concept of healthspan extension. Our findings that guinea pigs treated with dietary Rap had worse OA pathology raises concerns regarding the efficacy of dietary Rap as a lifeand healthspan-extending agent. Additional work is needed to investigate the role of alternative routes of administration or Rap analogs that may capture the positive benefits of Rap while minimizing offtarget effects. Our data also reveal that the contribution of mTOR in articular cartilage and chondrocyte metabolism is incompletely understood and additional research is needed to clarify the individual and combined role of $\mathrm{mTORC} 1$ and $\mathrm{mTORC} 2$ signaling in OA.

\section{Abbreviations}

OA: Osteoarthritis; mTOR: Mechanistic target of rapamycin; AMPK: AMP-activated protein kinase; Rap: Rapamycin; Met: Metformin; mTORC1: mTOR complex I; mTORC2: mTOR complex II; NBF: Neutral buffered formalin; $\mu C T$ : Micro computed tomography; ROI: Region of interest; IHC: Immunohistochemistry; OARSI: Osteoarthritis research society international; SD: Standard deviation; RPS6: Ribosomal protein S6; ADAMTS5: A disintegrin and metalloproteinase with thrombospondin motifs 5; MMP13: Matrix metalloproteinase 13; TMJ: Temporomandibular joint; IL-6: Interleukin 6; NFkB: Nuclear factor kappa-lightchain-enhancer of activated B-cells; ECM: Extracellular matrix.

\section{Supplementary Information}

The online version contains supplementary material available at https://doi. org/10.1186/s13075-021-02637-1.

Additional file 1: Figure S1. OA pathology increased from 5- to 8-months of age. A) Representative histological images of the medial tibial plateu of the knee joint from 5- and 8-month-old guinea pigs (scale bars are $0.5 \mathrm{~mm}$ and $0.25 \mathrm{~mm}$ in $5 x$ and $10 x$ images, respectively). B) Images were graded for total OARSI score and individual OARSI criteria. Comparisons for ACS were made using the non-parametric Mann-Whitney test. C) the lateral tibial plateau, medial femoral condyle and lateral femoral condyle were also graded for total OARSI score. Data $N=3$ for 5 -month and $N$ $=7$ for 8 -month. ${ }^{*} P<0.05$ vs Con. Figure S2. Trabecular bone changes in response to experimental diets. Trabecular thickness (A), spacing (B), and bone volume fraction (C) were measured using microCT. $N=4$ per group. ${ }^{*} P<0.05$ vs Con. Figure S3. Antibody reactivity with guinea pig articular cartilage was limited. Immunohistochemical staining was performed, and no reactivity was observed using primary antibodies against P-Akt Ser473 or P-AMPK Thr172.

\section{Acknowledgements}

The authors would like to thank Greg Friesenhahn at the Analytical Pharmacology and Drug Evaluation Core of the San Antonio Nathan Shock Center. We would also like to acknowledge the technical assistance from William Fairfield, Oscar Safairad, Alex Nichol, Nathan Carper, and Morgan Berland. We also acknowledge the assistance of the University of Wisconsin Translational 
Research Initiatives in Pathology (TRIP) laboratory supported by the UW Department of Pathology and Laboratory Medicine, UWCCC (P30 CA014520).

\section{Authors' contributions}

Study design: AK. Data collection: DM, CE, KS, MJ, and AK. Data analysis and interpretation: DM and AK. Manuscript preparation: DM and AK. The authors read and approved of the final manuscript.

\section{Funding}

The Konopka Laboratory was supported by the Campus Research Board at the University of Illinois and startup funds from the University of WisconsinMadison School of Medicine and Public Health, Department of Medicine, and funding from the National Institutes of Health grant R21 AG067464. This work was supported using facilities and resources from the William S. Middleton Memorial Veterans Hospital. The content is solely the responsibility of the authors and does not necessarily represent the official views of the $\mathrm{NIH}$, the Department of Veterans Affairs, or the US Government.

\section{Availability of data and materials}

Data from this study are available from the corresponding author, Adam Konopka, upon reasonable request.

\section{Declarations}

\section{Ethics approval and consent to participate}

Animal use was approved by the University of Illinois at Urbana-Champaign IACUC.

\section{Consent for publication \\ Not applicable.}

\section{Competing interests}

The authors declare that they have no competing interest.

\section{Author details}

'Division of Geriatrics and Gerontology, Department of Medicine, University of Wisconsin-Madison, Madison, Wisconsin, USA. ${ }^{2}$ Department of Kinesiology, University of Illinois at Urbana-Champaign, Champaign, Illinois, USA. ${ }^{3}$ Departments of Psychiatry and Pharmacology, University of Texas Health Science Center at San Antonio, San Antonio, Texas, USA. ${ }^{4}$ Department of Microbiology, Immunology, Pathology, Colorado State University, Fort Collins, Colorado, USA. ${ }^{5}$ Geriatric Research, Education, and Clinical Center, William S. Middleton Memorial Veterans Hospital, Madison, Wisconsin, USA.

Received: 16 June 2021 Accepted: 29 September 2021

Published online: 07 October 2021

\section{References}

1. Brown TD, Johnston RC, Saltzman CL, Marsh JL, Buckwalter JA. Posttraumatic osteoarthritis: a first estimate of incidence, prevalence, and burden of disease. J Orthop Trauma [Internet]. 2006;20(10):739-44 Available from: https://pubmed.ncbi.nlm.nih.gov/17106388/.

2. Aki T, Hashimoto K, Ogasawara M, Itoi E. A whole-genome transcriptome analysis of articular chondrocytes in secondary osteoarthritis of the hip. Agarwal S, editor. PLoS One. 2018;13(6):e0199734 Available from: https:// pubmed.ncbi.nlm.nih.gov/29944724/.

3. Xu Y, Barter MJ, Swan DC, Rankin KS, Rowan AD, Santibanez-Koref M, et al. Identification of the pathogenic pathways in osteoarthritic hip cartilage: commonality and discord between hip and knee OA. Osteoarthr Cartil. 2012;20(9):1029-38 Available from: https://pubmed.ncbi.nlm.nih.gov/ 22659600/.

4. Moon PM, Shao ZY, Wambiekele G, Appleton CTG, Laird DW, Penuela S, et al. Global deletion of pannexin 3 resulting in accelerated development of aging-induced osteoarthritis in mice. Arthritis Rheumatol. 2021; Available from: https://pubmed.ncbi.nlm.nih.gov/33426805/.

5. Yu D, Hu J, Sheng Z, Fu G, Wang Y, Chen Y, et al. Dual roles of misshapen/ NIK-related kinase (MINK1) in osteoarthritis subtypes through the activation of TGF $\beta$ signaling. Osteoarthr Cartil. 2020;28(1):112-21 Available from: https://pubmed.ncbi.nlm.nih.gov/31647983/.

6. Bouderlique T, Vuppalapati KK, Newton PT, Li L, Barenius B, Chagin AS. Targeted deletion of Atg5 in chondrocytes promotes age-related osteoarthritis. Ann Rheum Dis. 2016;75(3):627-31 Available from: https:// pubmed.ncbi.nlm.nih.gov/26438374/.

7. O'Conor CJ, Ramalingam S, Zelenski NA, Benefield HC, Rigo I, Little D, et al. Cartilage-specific knockout of the mechanosensory ion channel TRPV4 decreases age-related osteoarthritis. Sci Rep. 2016;6(July):1-10 Available from: https://doi.org/10.1038/srep29053.

8. Usmani SE, Ulici V, Pest MA, Hill TL, Welch ID, Beier F. Context-specific protection of TGFa null mice from osteoarthritis. Sci Rep. 2016;6(1):1-11 Available from: https://pubmed.ncbi.nlm.nih.gov/27457421/.

9. Loeser RF, Kelley KL, Armstrong A, Collins JA, Diekman BO, Carlson CS. Deletion of JNK enhances senescence in joint tissues and increases the severity of age-related osteoarthritis in mice. Arthritis Rheumatol. 2020;72(10):1679-88 Available from: https://pubmed.ncbi.nlm.nih.gov/ $32418287 /$

10. Zhang H, Wang H, Zeng C, Yan B, Ouyang J, Liu X, et al. mTORC1 activation downregulates FGFR3 and PTH/PTHrP receptor in articular chondrocytes to initiate osteoarthritis. Osteoarthr Cartil. 2017;25(6):952-63 Available from: https://pubmed.ncbi.nlm.nih.gov/28043938/.

11. Zhou S, Lu W, Chen L, Ge Q, Chen D, Xu Z, et al. AMPK deficiency in chondrocytes accelerated the progression of instability-induced and ageing-associated osteoarthritis in adult mice. Sci Rep. 2017;7(1):43245 Available from: https://pubmed.ncbi.nlm.nih.gov/28225087/.

12. Johnson SC, Rabinovich PS, Kaeberlin M. mTOR is a key modulator of ageing and age-related disease. Nature. 2013;493(7432):338-45 Available from: https://pubmed.ncbi.nlm.nih.gov/23325216/.

13. Salminen A, Kaarniranta K, Kauppinen A. Age-related changes in AMPK activation: role for AMPK phosphatases and inhibitory phosphorylation by upstream signaling pathways. Ageing Res Rev. 2016;28:15-26 Available from: https://pubmed.ncbi.nlm.nih.gov/27060201/.

14. Harrison DE, Strong R, Sharp ZD, Nelson JF, Astle CM, Flurkey K, et al. Rapamycin fed late in life extends lifespan in genetically heterogeneous mice. Nature. 2009;460(7253):392-5 Available from: https://pubmed.ncbi. nlm.nih.gov/19587680/

15. Arriola Apelo SI, Lamming DW. Rapamycin: an inhibiTOR of aging emerges from the soil of Easter island. J Gerontol Ser A Biol Sci Med Sci. 2016;71(7):841-9.

16. Strong R, Miller RA, Antebi A, Astle CM, Bogue M, Denzel MS, et al. Longer lifespan in male mice treated with a weakly estrogenic agonist, an antioxidant, an a-glucosidase inhibitor or a Nrf2-inducer. Aging Cell. 2016;15(5):872-84 Available from: https://pubmed.ncbi.nlm.nih.gov/ 27312235/.

17. Weiss R, Fernandez E, Liu Y, Strong R, Salmon AB. Metformin reduces glucose intolerance caused by rapamycin treatment in genetically heterogeneous female mice. Aging (Albany NY). 2018;10(3):386-401 Available from: https://pubmed.ncbi.nlm.nih.gov/29579736/.

18. Lamming DW, Ye L, Katajisto P, Goncalves MD, Saitoh M, Stevens DM, et al. Rapamycin-induced insulin resistance is mediated by mTORC2 loss and uncoupled from longevity. Science (80- ). 2012;335(6076):1638-43 Available from: https://pubmed.ncbi.nlm.nih.gov/22461615/.

19. Caramés B, Hasegawa A, Taniguchi N, Miyaki S, Blanco FJ, Lotz M. Autophagy activation by rapamycin reduces severity of experimental osteoarthritis. Ann Rheum Dis. 2012;71(4):575-81 Available from: https:// pubmed.ncbi.n/m.nih.gov/22084394/.

20. Takayama K, Kawakami Y, Kobayashi M, Greco N, Cummins JH, Matsushita T, et al. Local intra-articular injection of rapamycin delays articular cartilage degeneration in a murine model of osteoarthritis. Arthritis Res Ther. 2014;16(6):482 Available from: https://pubmed.ncbi.nlm.nih.gov/25403 236/.

21. Cheng N-T, Guo A, Cui Y-P. Intra-articular injection of Torin 1 reduces degeneration of articular cartilage in a rabbit osteoarthritis model. Bone Joint Res. 2016;5(6):218-24 Available from: https://pubmed.ncbi.nlm.nih. gov/27301478/.

22. Zhang Y, Vasheghani F, Li Y, Blati M, Simeone K, Fahmi H, et al. Cartilagespecific deletion of mTOR upregulates autophagy and protects mice from osteoarthritis. Ann Rheum Dis. 2015;74(7):1432-40 Available from: https://pubmed.ncbi.nlm.nih.gov/24651621/. 
23. Chen J, Crawford R, Xiao Y. Vertical inhibition of the PI3K/Akt/mTOR pathway for the treatment of osteoarthritis. J Cell Biochem. 2013;114(2):245-9.

24. Pal B, Endisha H, Zhang Y, Kapoor M. mTOR: a potential therapeutic target in osteoarthritis? Drugs R D. 2015;15(1):27-36 Available from: https:// pubmed.ncbi.nlm.nih.gov/25688060/.

25. Chen K, Lin ZW, He SM, Wang CQ, Yang JC, Lu Y, et al. Metformin inhibits the proliferation of rheumatoid arthritis fibroblast-like synoviocytes through IGF-IR/PI3K/AKT/m-TOR pathway. Biomed Pharmacother. 2019;115(April 2018):1-8 Available from: https://pubmed.ncbi.nlm.nih. gov/31028998/

26. Wang C, Yang Y, Zhang Y, Liu J, Yao Z, Zhang C. Protective effects of metformin against osteoarthritis through upregulation of SIRT3-mediated PINK1/Parkin-dependent mitophagy in primary chondrocytes. Biosci Trends. 2018;12(6):605-12 Available from: https://pubmed.ncbi.nlm.nih. gov/30584213/.

27. Petursson F, Husa M, June R, Lotz M, Terkeltaub R, Liu-Bryan R. Linked decreases in liver kinase B1 and AMP-activated protein kinase activity modulate matrix catabolic responses to biomechanical injury in chondrocytes. Arthritis Res Ther. 2013;15(4):R77 Available from: https://pubmed. ncbi.nlm.nih.gov/23883619/.

28. Li J, Zhang B, Liu W-X, Lu K, Pan H, Wang T, et al. Metformin limits osteoarthritis development and progression through activation of AMPK signalling. Ann Rheum Dis. 2020;79(5):635-45 Available from: https://pubmed. ncbi.nlm.nih.gov/32156705/.

29. Wang Y, Hussain SM, Wluka AE, Lim YZ, Abram F, Pelletier J-P, et al. Association between metformin use and disease progression in obese people with knee osteoarthritis: data from the Osteoarthritis Initiativea prospective cohort study. Arthritis Res Ther. 2019;21(1):127 Available from: https://pubmed.ncbi.nlm.nih.gov/31126352/.

30. Bendele AM, Hulman JF. Effects of body weight restriction on the development and progression of spontaneous osteoarthritis in guinea pigs. Arthritis Rheum. 1991;34(9):1180-4 Available from: https://pubmed.ncbi. nlm.nih.gov/1930336/.

31. Bendele AM, White SL, Hulman JF. Osteoarthrosis in guinea pigs: histopathologic and scanning electron microscopic features. Lab Anim Sci. 1989;39(2):115-21 Available from: https://pubmed.ncbi.nlm.nih.gov/ 2709799/.

32. Santangelo KS, Pieczarka EM, Nuovo GJ, Weisbrode SE, Bertone AL. Temporal expression and tissue distribution of interleukin-1 $\beta$ in two strains of guinea pigs with varying propensity for spontaneous knee osteoarthritis. Osteoarthr Cartil. 2011;19(4):439-48.

33. Santangelo KS, Bertone AL. Effective reduction of the interleukin-1 $\beta$ transcript in osteoarthritis-prone guinea pig chondrocytes via short hairpin RNA mediated RNA interference influences gene expression of mediators implicated in disease pathogenesis. Osteoarthr Cartil. 2011;19(12):144957 Available from: https://www.ncbi.nlm.nih.gov/pmc/articles/PMC36 24763/pdf/nihms412728.pdf.

34. Santangelo KS, Nuovo GJ, Bertone AL. In vivo reduction or blockade of interleukin- $1 \beta$ in primary osteoarthritis influences expression of mediators implicated in pathogenesis. Osteoarthr Cartil. 2012;20(12):1610-8.

35. Gilbert SJ, Duance VC, Mason DJ. Tumour necrosis factor a up-regulates protein kinase R (PKR)-activating protein (PACT) and increases phosphorylation of PKR and eukaryotic initiation factor 2-a in articular chondrocytes. Biochem Soc Trans. 2002;30(6):886-9.

36. Yuasa T, Otani T, Koike T, Iwamoto M, Enomoto-Iwamoto M. Wnt/Bcatenin signaling stimulates matrix catabolic genes and activity in articular chondrocytes: its possible role in joint degeneration. Lab Investig. 2008;88(3):264-74.

37. Scott JL, Gabrielides C, Davidson RK, Swingler TE, Clark IM, Wallis GA, et al. Superoxide dismutase downregulation in osteoarthritis progression and end-stage disease. Ann Rheum Dis. 2010;69(8):1502-10.

38. Radakovich LB, Marolf AJ, Shannon JP, Pannone SC, Sherk VD, Santangelo KS. Development of a microcomputed tomography scoring system to characterize disease progression in the Hartley guinea pig model of spontaneous osteoarthritis. Connect Tissue Res. 2018;59(6):523-33 Available from: https://pubmed.ncbi.nlm.nih.gov/29226725/.

39. Kraus VB, Huebner JL, DeGroot J, Bendele A. The OARSI histopathology initiative - recommendations for histological assessments of osteoarthritis in the guinea pig. Osteoarthr Cartil. 2010;18(SUPPL. 3):S35-52 Available from: https://doi.org/10.1016/j.joca.2010.04.015.
40. Bendele AM. Animal models of osteoarthritis. In: Journal of Musculokeletal Neuron Interaction [Internet]; 2001. p. 363-76. Available from: https:// pubmed.ncbi.nlm.nih.gov/15758487/.

41. Radakovich LB, Marolf AJ, Culver LA, Santangelo KS. Calorie restriction with regular chow, but not a high-fat diet, delays onset of spontaneous osteoarthritis in the Hartley guinea pig model. Arthritis Res Ther. 2019;21(1):145 Available from: https://pubmed.ncbi.nlm.nih.gov/31196 $172 \%$

42. Martin-Montalvo A, Mercken EM, Mitchell SJ, Palacios HH, Mote PL, Scheibye-Knudsen M, et al. Metformin improves healthspan and lifespan in mice. Nat Commun. 2013;4(1):2192 Available from: https://pubmed. ncbi.nlm.nih.gov/23900241/.

43. Miller RA, Harrison DE, Astle CM, Baur JA, Boyd AR, de Cabo R, et al. Rapamycin, but not resveratrol or simvastatin, extends life span of genetically heterogeneous mice. J Gerontol Ser A. 2011;66A(2):191-201 Available from: https://pubmed.ncbi.nlm.nih.gov/20974732/.

44. De Oliveira MA, Martins E, Martins F, Wang Q, Sonis S, Demetri G, et al. Clinical presentation and management of mTOR inhibitor-associated stomatitis. Oral Oncol. 2011;47(10):998-1003 Available from: https:// pubmed.ncbi.n/m.nih.gov/21890398/.

45. Wilkinson JE, Burmeister L, Brooks SV, Chan C-C, Friedline S, Harrison DE, et al. Rapamycin slows aging in mice. Aging Cell. 2012;11(4):675-82 Available from: http://doi.wiley.com/10.1111/j.1474-9726.2012.00832.x.

46. Fraser KW. Effect of storage in formalin on organ weights of rabbits. New Zeal J Zool. 1985;12(2):169-74.

47. Tardif S, Ross C, Bergman P, Fernandez E, Javors M, Salmon A, et al. Testing efficacy of administration of the antiaging drug rapamycin in a nonhuman primate, the common marmoset. J Gerontol Ser A Biol Sci Med Sci. 2015;70(5):577-88 Available from: https://pubmed.ncbi.nlm.nih.gov/ 25038772/.

48. Fernandez E, Ross C, Liang H, Javors M, Tardif S, Salmon AB. Evaluation of the pharmacokinetics of metformin and acarbose in the common marmoset. Pathobiol Aging Age-related Dis. 2019;9(1):1657756 Available from: https://pubmed.ncbi.nlm.nih.gov/31497263/.

49. Buie HR, Campbell GM, Klinck RJ, MacNeil JA, Boyd SK. Automatic segmentation of cortical and trabecular compartments based on a dual threshold technique for in vivo micro-CT bone analysis. Bone. 2007;41(4):505-15 Available from: https://pubmed.ncbi.nlm.nih.gov/ $17693147 /$

50. Li Y, Yang J, Liu Y, Yan X, Zhang Q, Chen J, et al. Inhibition of mTORC1 in the rat condyle subchondral bone aggravates osteoarthritis induced by the overly forward extension of the mandible. Am J Transl Res. 2021;13(1):270-85 Available from: https://pubmed.ncbi.nlm.nih.gov/ $33527023 /$

51. Nair A, Jacob S. A simple practice guide for dose conversion between animals and human. J Basic Clin Pharm. 2016;7(2):27.

52. Aggarwal D, Fernandez ML, Soliman GA. Rapamycin, an mTOR inhibitor, disrupts triglyceride metabolism in guinea pigs. Metabolism. 2006;55(6):794-802 Available from: https://pubmed.ncbi.nlm.nih.gov/ $16713440 \%$

53. Lang CM, Munger BL. Diabetes mellitus in the guinea pig. Diabetes. 1976;25(5):434-43.

54. Podell BK, Ackart DF, Richardson MA, DiLisio JE, Pulford B, Basaraba RJ. A model of type 2 diabetes in the guinea pig using sequential dietinduced glucose intolerance and streptozotocin treatment. DMM Dis Model Mech. 2017;10(2):151-62.

55. Chen YJ, Chan DC, Lan KC, Wang CC, Chen CM, Chao SC, et al. PPARY is involved in the hyperglycemia-induced inflammatory responses and collagen degradation in human chondrocytes and diabetic mouse cartilages. J Orthop Res. 2015;33(3):373-81 Available from: https://pubmed. ncbi.nlm.nih.gov/25410618/.

56. Liang H, Wang H, Luo L, Fan S, Zhou L, Liu Z, et al. Toll-like receptor 4 promotes high glucose-induced catabolic and inflammatory responses in chondrocytes in an NF-KB-dependent manner. Life Sci. 2019;228(April):258-65 Available from: https://pubmed.ncbi.nlm.nih.gov/ 30953645/.

57. Ribeiro M, López de Figueroa P, Blanco FJ, Mendes AF, Caramés B. Insulin decreases autophagy and leads to cartilage degradation. Osteoarthr Cartil. 2016;24(4):731-9. 
58. Kelley KM, Johnson TR, Ilan J, Moskowitz RW. Glucose regulation of the IGF response system in chondrocytes: induction of an IGF-l-resistant state. Am J Physiol. 1999;276(4 45-4):1164-71.

59. Rosa SC, Rufino AT, Judas FM, Tenreiro CM, Lopes MC, Mendes AF. Role of glucose as a modulator of anabolic and catabolic gene expression in normal and osteoarthritic human chondrocytes. J Cell Biochem. 2011;112(10):2813-24

60. Rufino AT, Ribeiro M, Ferreira JP, Judas F, Mendes AF. Hyperglycemia and hyperinsulinemia-like conditions independently induce inflammatory responses in human chondrocytes. J Funct Morphol Kinesiol. 2017;2(2):15. https://www.mdpi.com/2411-5142/2/2/15.

61. Rosa SC, Gonçalves J, Judas F, Mobasheri A, Lopes C, Mendes AF. Impaired glucose transporter-1 degradation and increased glucose transport and oxidative stress in response to high glucose in chondrocytes from osteoarthritic versus normal human cartilage. Arthritis Res Ther. 2009;11(3):1-11.

62. Ribeiro M, López de Figueroa P, Nogueira-Recalde U, Centeno A, Mendes AF, Blanco FJ, et al. Diabetes-accelerated experimental osteoarthritis is prevented by autophagy activation. Osteoarthr Cartil. 2016;24(12):2116-25

63. Reifsnyder PC, Flurkey K, Te A, Harrison DE. Rapamycin treatment benefits glucose metabolism in mouse models of type 2 diabetes. Aging (Albany
NY). 2016;8(11):3120-30 Available from: https://pubmed.ncbi.nlm.nih. gov/27922820/.

64. Watson PJ, Hall LD, Malcolm A, Tyler JA. Degenerative joint disease in the guinea pig: Use of magnetic resonance imaging to monitor progression of bone pathology. Arthritis Rheum. 1996;39(8):1327-37 Available from: https://pubmed.ncbi.nlm.nih.gov/8702441/.

65. Xian L, Wu X, Pang L, Lou M, Rosen C, Qui T, et al. Matrix IGF-1 regulates bone mass by activation of mTOR in mesenchymal stem cells. Nat Med. 2012;18(7):1095-101 Available from: https://pubmed.ncbi.nlm.nih.gov/ 22729283/.

66. Hamrick MW, Ding KH, Ponnala S, Ferrari SL, Isales CM. Caloric restriction decreases cortical bone mass but spares trabecular bone in the mouse skeleton: Implications for the regulation of bone mass by body weight. J Bone Miner Res. 2008;23(6):870-8 Available from: https://pubmed.ncbi. nlm.nih.gov/18435579/.

\section{Publisher's Note}

Springer Nature remains neutral with regard to jurisdictional claims in published maps and institutional affiliations.
Ready to submit your research? Choose BMC and benefit from:

- fast, convenient online submission

- thorough peer review by experienced researchers in your field

- rapid publication on acceptance

- support for research data, including large and complex data types

- gold Open Access which fosters wider collaboration and increased citations

- maximum visibility for your research: over 100M website views per year

At BMC, research is always in progress.

Learn more biomedcentral.com/submissions 